\section{Five years REACH}

\author{
Jochen Flasbarth
}

\section{Editorial}

On June, 1st, we celebrated five years experience since the European REACH Regulation [1] entered into force. The experience is mainly positive: In nearly 29,000 technical dossiers for approximately 5,900 substances, registrants submitted a huge amount of information on uses, properties, hazards, toxicological and ecotoxicological effects to the European Chemicals Agency (ECHA) in Helsinki. These registrations include all substances with a manufacturing or import volume of more than 1,000 tons per year and registrant, all substances that are carcinogenic, mutagenic or toxic for reproduction which are intended to stay on the EU-market, and some more important chemicals.

It was a really hard challenge for companies to meet the deadline for registration and the REACH information requirements. Although we, and also ECHA [2] are not completely satisfied with the quality of many dossiers and the way the information requirements were interpreted, we'd like to congratulate the world-wide chemical industry for managing this challenge in time.

The task for authorities is to prioritise substances for regulatory activities. For ECHA this is the dossier evaluation, for Member States authorities the substance evaluation and for all authorities elaborating proposals to identify substances of very high concern (SVHC), and candidates for authorisation and restrictions. Some of these tasks are already in the beginning (e.g. substance evaluation), others are ongoing, (e.g. the identification of SVHC). By September, 1st, 84 SVHC are included in the candidate list, and 14 substances are included in Annex $\mathrm{XIV}$ and therefore will be subject for authorisation in future. To elaborate the proposals and to agree the measures in the Member State Committee was not an easy task - and therefore we congratulate also the Member States authorities, and especially ECHA.

Reflecting five years experiences, we see options for some improvements. Among other suggestions, the most important is to strengthen the role of ECHA: As a last measure for incomplete registration dossiers, the option to deny a registration should be given to ECHA. We also suggest extending the possibility to access the information stored in the REACH databases in Helsinki to include information on research issues - with the exception of core confidential business information. This may be a great opportunity for the chemical industry to accept the challenge of discussing their research results with the scientific community and a great chance to improve our knowledge on sustainable chemicals.

With this editorial, Environmental Sciences Europe is starting a collection "five years REACH" edited by Christoph Schulte. We already asked for contributions focusing on the first experiences of certain stakeholders (Authorities, CEFIC, NGOs, Members of ECHAs Committees), and specific issues like nanomaterials, pbt-substances, or endocrine disruptors. Additional manuscripts on related topics are welcome. When REACH is celebrating the sixths birthday in June 2013, the series will be finalised.

\section{Competing interests}

The author declares that he has no competing interests.

Received: 20 September 2012 Accepted: 30 September 2012 Published: 22 October 2012

\section{References}

1. Regulation (EC) No 1907/2006 of the European Parliament and of the Council of 18 December 2006 concerning the Registration, Evaluation, Authorisation and Restriction of Chemicals (REACH), establishing a European Chemicals Agency, amending Directive 1999/45/EC and repealing Council Regulation (EEC) No 793/93 and Commission Regulation (EC) No 1488/94 as well as Council Directive 76/769/EEC and Commission Directives 91/155/ EEC, 93/67/EEC, 93/105/EC and 2000/21/EC. Official Journal of the EU 2006, L396:1-849.

2. European Chemicals Agency: Report on the Operation of REACH and CLP. Helsinki: 2011.

\section{doi:10.1186/2190-4715-24-32}

Cite this article as: Flasbarth: Five years REACH. Environmental Sciences Europe 2012 24:32. 